\title{
REFERENCE RANGES FOR LYMPHOCYTE SUBSETS IN ADULTS FROM WESTERN INDIA: INFLUENCE OF SEX, AGE AND METHOD OF ENUMERATION
}

BIBHU R. DAS, APARNA A. BHANUSHALI, R. KHADAPKAR, KANCHAN D. JESWANI', MITA BHAVSAR ${ }^{1}$, A. DASGUPTA ${ }^{1}$

\section{ABSTRACT}

BACKGROUND: The enumeration of absolute CD4 counts is of primary importance, since therapeutic protocols for HIV1 patients are based on these. AIMS: To establish reference ranges for the CD4 and CD8 T-lymphocytes in the Indian population. SETTINGS AND DESIGN: Enumeration of absolute numbers and percentages of lymphocyte subsets was performed in 252 healthy adult Indians. METHODS AND MATERIALS: The assays for SPT were carried out using the Beckman EPICS XL-MCL flow cytometer and the cytostat tetraCHROME reagent containing CD45/CD8/CD4/CD3 monoclonal antibodies. For comparison with DPT the absolute lymphocyte count was obtained using the Coulter STK-S fully automated hematology analyzer. STATISTICAL ANALYSIS: Regression analysis and Students $t$ test were used for data analysis. RESULTS: Median values were as follows; absolute CD3 counts $1446 \mathrm{cells} / \mathrm{mm} 3$ (total), $1361 \mathrm{cells} / \mathrm{mm} 3$ (males) and $1511 \mathrm{cells} / \mathrm{mm} 3$ (females); absolute CD4 counts are $771 \mathrm{cells} / \mathrm{mm} 3$ (total), $705 \mathrm{cells} /$ mm3 (males) and 839 cells $/ \mathrm{mm} 3$ (females); absolute CD8 counts are 555 cells/mm3 (total), 552 cells $/ \mathrm{mm} 3$ (males) and 561 cells/mm3 (females). The median CD4/CD8 ratio for the total samples was 1.34, for males 1.22 and for females 1.49. CONCLUSIONS: In this study we have established reference ranges for normal Indian adults using the fully automated Single Platform Technology. The lymphocyte subsets values of our population are closer to those of the population from Botswana and China rather than the Western population. The absolute CD3 and CD4 counts and the CD4:CD8 ratio are higher in females than in males. Consistently higher values are obtained by the DPT as compared to the SPT.

Key words: CD4 T lymphocytes, CD-8 T-lymphocytes, reference range, single platform flow cytometry.

Research and Development, 'Department of

Hematology, SRL Ranbaxy Ltd, Plot No 113,

MIDC,15th Street, Andheri (East),

Mumbai-400 093, India

Correspondence:

Dr. B. R. Das, SRL Ranbaxy Ltd, Plot No 113, MIDC, 15th

Street, Andheri (East), Mumbai-400 093, India.

E-mail: brdas@srlranbaxy.co.in

\section{INTRODUCTION}

The progressive loss of CD4 T lymphocytes through virally mediated cell destruction is the predominant pathophysiological manifestation of the human immunodeficiency virus 1 
(HIV1). ${ }^{[1]}$ According to the Indian National AIDS Control Organization (NACO) estimates, 5.134 million people were living with HIV in 2004. ${ }^{[2]}$ Therapeutic protocols for HIV1 patients are based on CD4 lymphocyte absolute counts, which are used as a prognostic marker ${ }^{[3]}$ and also to monitor the effectiveness of antiretroviral treatment. Hence reliable methods for enumeration of lymphocyte subsets are of great importance, as new drugs may induce rapid and dramatic modifications of otherwise relatively stable or regularly decreasing lymphocyte counts. ${ }^{[4,5]}$

The enumeration can be accomplished using single or dual platform counting technologies. However it is the single platform approach (SPT), that is considered as the gold standard for absolute cell assessments. ${ }^{[6]}$ In a multisite trial, ${ }^{[7]}$ comparison of two different SPT methods with a predicate two-color assay in which the absolute lymphocyte count was derived by conventional hematology was employed. They concluded that the fully automated Beckman Coulter tetraONE system resulted in a small but significant improvement in the within laboratory precision of the CD4 and CD8 cell counts and percentages. However a recent study ${ }^{[8]}$ states that they would prefer DPT over SPT for activation markers (DR, CD25 and CD38) of HIV patients.

There have been studies from northeast India, ${ }^{[9]}$ from the Western region ${ }^{[10]}$ and a multi centric study, ${ }^{[11]}$ however, given the differences in the technology and ethnicity of the Indian population a need was felt to establish immunohematological reference ranges for the Indian setting based on NCCLS guidelines. We have utilized the fully automated
Beckman Coulter tetraONE system employing CD45 lymphocyte gating, automated analysis and Flow-Count fluorospheres to establish the reference ranges.

\section{MATERIALS AND METHODS}

Subjects: A total of 252 adults from Western Maharashtra (120 men aged from 18 to 56 years and 132 women aged from 15 to 56 years) were enrolled in this study. Individuals included were healthy adults between 15 and 60 years of age presenting for a routine health check-up. The participants had to fill a questionnaire regarding loss/gain of weight, vaccination, infection in the past 4 weeks including viral, bacterial, fungal, and other pathogens, use of antibiotics in the past 4 weeks, hospitalization within the past 2 years, and history of medication, including analgesics, nonsteroidal anti-inflammatory agents, antiulcer drugs, anti-hypertensive drugs, and other cardiovascular drugs. Subjects who reported a positive history for any of these items were excluded from the study. Blood specimens were collected after an overnight fast of $12 \mathrm{hrs}$ by veni-puncture using the vacutainer system from Becton Dickinson (Franklin Lakes, NJ USA) in the anticoagulant EDTA. The samples were analyzed on the day of the collection.

Instrumentation: The hematology instrument used for determining absolute lymphocyte count by the dual platform technology (DPT) was a Coulter STK-S which is a fully automated hematology analyzer and quantitatively measures and computes hematological quantities including a full "five-part" differential. The flow cytometry analysis was performed with the Beckman Coulter EPICS XL-MCL flow 
cytometer (Beckman Coulter, Miami, USA.) using the tetraONE SYSTEM software.

\section{Instrument performance was ensured by}

\section{the following:}

- internal validation for intra-assay (1 sample, 20 times in one run) and inter-assay variation ( 1 sample, 5 times in five runs). The \% coefficient of variation was less than $10 \%$.

- internal quality assurance exercises consisting of daily runs of internal controls and periodic calibration of equipment: Instrument fluidics and alignment check was done by running Flowcheck beads. Beckman Immunotrol Normal and Beckman Immunotrol Low were used as two level quality controls provided by the manufacturer (Beckman Coulter, Miami, USA.).

- testing numerous samples for concordance of results.

\section{Flow cytometric immunophenotyping:}

Dual Platform Method: Absolute lymphocyte counts were determined as the product of the WBC count and percent lymphocyte differential as measured by the Coulter STK-S. For specimen preparation $50 \mu \mathrm{l}$ whole blood specimens were incubated with premixed antibodies for $20 \mathrm{~min}$ and erythrocytes lysed with the Immunoprep ${ }^{\mathrm{TM}}$ reagent system (Beckmann Coulter). The percentage of lymphocytes expressing CD3 and CD4 or CD3 and CD8 were determined according to the published guidelines for Flow Cytometric Immunophenotyping. ${ }^{[12,13]}$ The dual platform method was performed using the 4 color antibody reagent as mentioned for the single platform method.

However absolute $\mathrm{CD}^{+} \mathrm{CD}^{+}$and $\mathrm{CD}^{+} \mathrm{CD}^{+}$ were calculated by multiplying the specific subset percentage by the absolute lymphocyte count.

Single Platform Method: The assay was performed in the following manner for the single platform technology (SPT). $50 \mu \mathrm{l}$ whole blood specimens were incubated with $5 \mu \mathrm{l}$ of reagent CYTO-STAT tetraCHROME containing CD45-FITC/CD4-RD1/CD8-ECD/ CD3-PC5 monoclonal antibodies. Red Blood Cells are lysed with the Immunoprep ${ }^{\mathrm{TM}}$ reagent system (Beckmann Coulter), $50 \mu$ flow-count fluorosphere added and analyzed using CS3D flow count protocol. The tetraOne system software was used for gating and analysis of CD4/CD8. The software provides 3-dimensional lymphocyte gating using forward scatter, side scatter and CD45 [Figure 1]. Flow count fluorospheres provide real live absolute counts of lymphocytes. To obtain the absolute count determination on the EPICS XL flow cytometer, at least 1,000 fluorospheres are counted; the absolute count for the whole blood sample is then automatically calculated using the following formula:

Absolute Count (cells/ $\mu \mathrm{L})$

$\frac{\text { Total number of cells counted }}{\text { Total number of fluorospheres counted }} \times \begin{aligned} & \text { Flow }- \text { count } \\ & \text { fluorospheres assesed } \\ & \text { concentration }\end{aligned}$

\section{Statistical Analysis}

Medians, means, ranges, 2.5th to 97.5 th percentiles, standard deviation, standard errors, and $95 \%$ confidence intervals were calculated for each parameter. The data was divided into class intervals and if it followed the Gaussian distribution then the reference range was given by Mean $\pm 2 S D$. However if 
the data followed a non-Gaussian distribution, then the reference range was defined as the central $95 \%$ of the area under the distribution curve of values (from 2.5 to 97.5 percentile). Regression analysis was done to compare the correlation between the two techniques and between genders. The Students $t$ test was used to compare the distribution of the T-cell subsets between genders, and also applied to check if there is any statistically significant difference in the values obtained by the two techniques. $P$ values of $<0.05$ were considered significant.

\section{RESULTS}

Of the 252 samples analyzed, 120 were males and 132 were females. These samples were selected on the basis of the exclusion criteria as mentioned earlier. The median age of males was 26 years and that for females was 25 years. Summary statistics for white blood cells (WBC), lymphocyte counts and percentage as well as absolute counts of lymphocyte subsets in the total sample are given in Table 1. Gender specific values of these parameters are given in Table 2. Table 2 also reflects the significance of these parameters with respect to sex. The median \%CD3 value in the total sample was $73 \%$, (in males $72 \%$ and in females $75 \%$ ). The median absolute CD3 counts in total population was 1446 cells $/ \mathrm{mm}^{3}$ (in males 1361 cells $/ \mathrm{mm}^{3}$ and in females 1511 cells $/ \mathrm{mm}^{3}$ ). The overall median \%CD4 count was 39\%, (in males 37\% and in females $42 \%$ ). The median absolute CD4 counts in the total population was 771 cells/ $\mathrm{mm}^{3}$ (in males 705 cells $/ \mathrm{mm}^{3}$ and in females 839 cells $\left./ \mathrm{mm}^{3}\right)$. The median \%CD8 count was $29 \%$ (in males $29 \%$ and in females $28 \%$ ). The median absolute CD8 counts in total population was 555 cells $/ \mathrm{mm}^{3}$ (in males 552 cells $/ \mathrm{mm}^{3}$ and
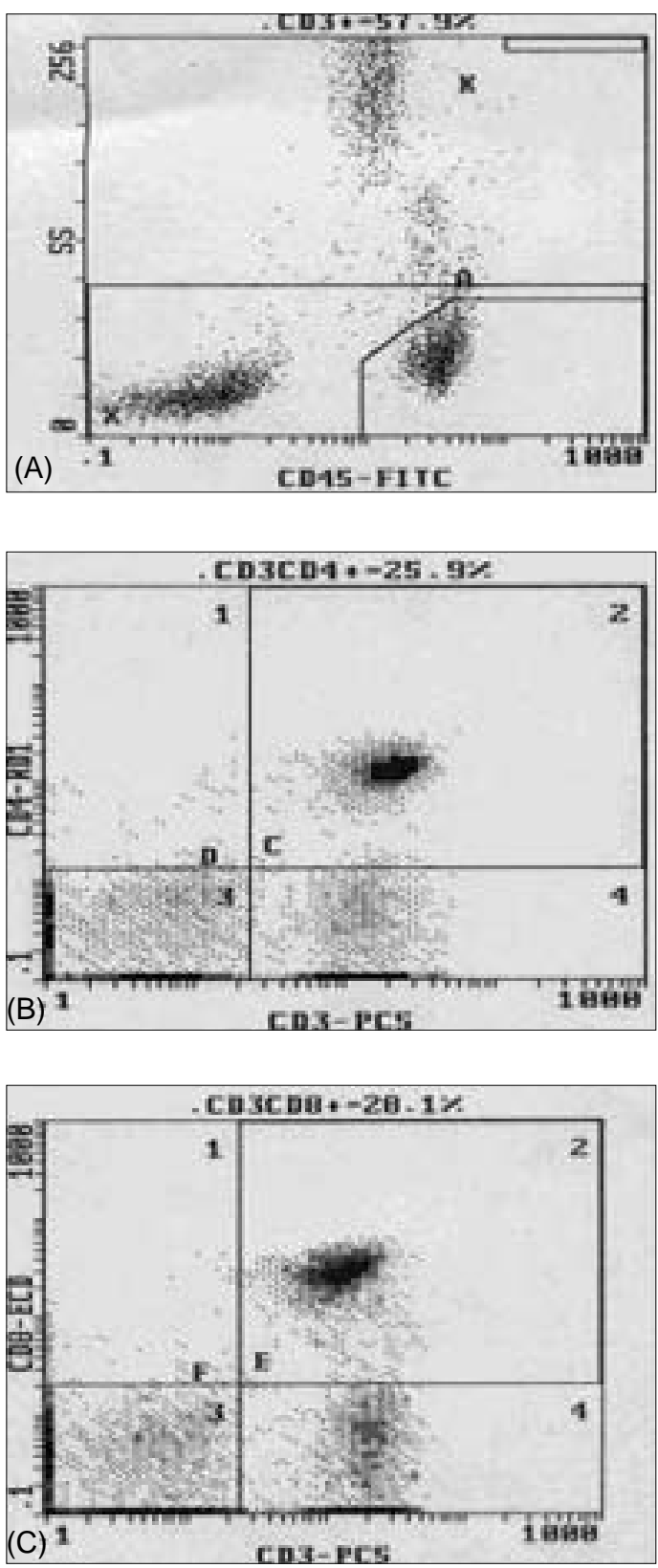

Figure 1: Representative flow Cytometry dot plot, (A) Lymphocyte gate, identified as having bright CD 45+FITC fluorescence and low side scatter, (B) This histogram depicts CD3+/CD4+ (positivePC5/ RD1) fluorescence seen in the quadrant 2, (C) CD3+/ CD8+ (positive PC5/ECD fluorescence) seen in quadrant 2 
in females 561 cells $/ \mathrm{mm}^{3}$ ). The median CD4/ CD8 ratio for the total population was 1.34 (for males 1.22 and for females 1.49). When the parameters were analyzed on the basis of gender, statistically significant differences were seen, for absolute counts of CD3 lymphocytes $(P=0.008)$ and absolute CD4 counts $(P<0.001)$, but not for absolute CD8 counts $(P=0.456)$. The median values were higher in females. The CD4:CD8 ratio was also higher in females $(P<0.001)$. No significant differences were found between age and the different parameters studied [Figure 2].

Comparative values obtained by the single platform technology and the double platform technology are also given. The absolute CD3 count in the total population shows a difference of greater than 100 cells $/ \mu 1$ between SPT and DPT, and in both CD4 and CD8 absolute counts

Table 1: Statistics of the data on lymphocyte sub-populations in the total samples

\begin{tabular}{lccccccc}
\hline Parameters & Mean & Median & $S D$ & $S E$ & $95 \%$ Cl $^{a}$ & Reference range $^{\text {Data range }}$ \\
\hline WBC & 7085 & 7000 & 1318.57 & 82.88 & $6923-7248$ & $4600-9800^{*}$ & $4000-10,500$ \\
Lympho & 31.3 & 31.4 & 6.58 & 0.41 & $30.49-32.11$ & $18.9-45^{*}$ & $15.8-48$ \\
CD3\% & 73.38 & 73.3 & 6.66 & 0.42 & $72.56-74.20$ & $60.06-86.69^{\dagger}$ & $50.8-90.4$ \\
CD3 - SPT & 1483 & 1446 & 387.75 & 24.37 & $1435-1531$ & $821-2418^{*}$ & $620-2562$ \\
CD3 - DPT & 1610 & 1565 & 423.69 & 26.63 & $1558-1662$ & $886-2511^{*}$ & $688-2695$ \\
CD4\% & 39.38 & 38.8 & 6.45 & 0.41 & $38.59-40.17$ & $28.2-55.2^{*}$ & $24.2-65$ \\
CD4 - SPT & 794 & 771 & 228.68 & 14.37 & $766-823$ & $337-1252^{\dagger}$ & $374-1493$ \\
CD4 - DPT & 860 & 854 & 243.85 & 15.33 & $830-890$ & $373-1348^{\dagger}$ & $369-1642$ \\
CD8\% & 29.04 & 28.6 & 6.46 & 0.41 & $28.24-29.84$ & $16.11-41.96^{\dagger}$ & $11.6-50.6$ \\
CD8 - SPT & 587 & 555 & 206.51 & 12.98 & $562-613$ & $216-1077^{*}$ & $172-1476$ \\
CD8 - DPT & 638 & 584 & 218.61 & 13.74 & $611-665$ & $252-1165^{*}$ & $207.67-1458$ \\
Ratio & 1.45 & 1.34 & 0.52 & 0.03 & $1.39-1.51$ & $0.42-2.48^{*}$ & $0.54-3.89$ \\
\hline
\end{tabular}

a $95 \%$ confidence interval, ${ }^{\star} 2.5^{\text {th }}$ and $97.5^{\text {th }}$ percentile values of the sample, ${ }^{\dagger}$ Mean $\pm 2 S D$, Minimum and Maximum of sample values

Table 2: Statistics of the data of various on lymphocyte sub-populations in males/females

\begin{tabular}{|c|c|c|c|c|c|c|c|c|c|}
\hline Parameters & Group & Mean & Median & $S D$ & $S E$ & $95 \% \mathrm{Cl}^{a}$ & Reference range & Data range $^{c}$ & $P$-value \\
\hline \multirow[t]{2}{*}{ WBC } & Male & 6981 & 6900 & 1279.47 & 116.32 & $6753-7209$ & $4600-9800^{*}$ & $4400-10300$ & \\
\hline & Female & 7133 & 7200 & 1349.40 & 117.44 & $6902-7363$ & $4500-9600^{*}$ & $4000-10500$ & 0.120 \\
\hline \multirow[t]{2}{*}{ Lympho } & Male & 31.35 & 31.20 & 6.54 & 0.59 & $30.18-32.51$ & $17.3-44.8^{*}$ & $15.8-48$ & \\
\hline & Female & 31.16 & 31.55 & 6.70 & 0.58 & $30.02-32.31$ & $19.3-46.6^{*}$ & $18.9-47.2$ & 0.451 \\
\hline \multirow[t]{2}{*}{ CD3\% } & Male & 71.90 & 71.90 & 6.23 & 0.57 & $70.79-73.01$ & $59.43-84.36^{\dagger}$ & $50.8-86.3$ & \\
\hline & Female & 74.50 & 75.35 & 6.91 & 0.60 & $73.32-75.68$ & $60.68-88.32^{\dagger}$ & $56.7-90.4$ & $<0.001$ \\
\hline \multirow[t]{2}{*}{ CD3 - SPT } & Male & 1423 & 1361 & 353.57 & 32.14 & $1360-1486$ & $897-2341^{*}$ & $813-2420$ & \\
\hline & Female & 1525 & 1512 & 410.39 & 35.72 & $1455-1595$ & $668-2425^{\star}$ & $620-2562$ & 0.008 \\
\hline \multirow[t]{2}{*}{ CD3 - DPT } & Male & 1554 & 1486 & 405.48 & 36.86 & $1482-1627$ & $1007-2479^{*}$ & $801.24-2639.25$ & \\
\hline & Female & 1640 & 1617 & 438.37 & 38.15 & $1565-1715$ & $755-2689^{\star}$ & $688.25-2593.51$ & 0.008 \\
\hline \multirow[t]{2}{*}{ CD4\% } & Male & 36.89 & 36.60 & 5.48 & 0.50 & $35.91-37.87$ & $27.9-50.5^{\star}$ & $24.2-55.1$ & \\
\hline & Female & 41.38 & 41.60 & 6.52 & 0.57 & $40.27-42.49$ & $28.5-55.1^{*}$ & $27.5-65$ & $<0.001$ \\
\hline \multirow[t]{2}{*}{ CD4 - SPT } & Male & 727 & 705 & 186.73 & 16.98 & $694-760$ & $354-1100^{\dagger}$ & $374-1398$ & \\
\hline & Female & 845 & 839 & 244.67 & 21.29 & $804-888$ & $356-1335^{\dagger}$ & $380-1493$ & $<0.001$ \\
\hline \multirow[t]{2}{*}{ CD4 - DPT } & Male & 794 & 761 & 211.64 & 19.24 & $756-832$ & $371-1217^{\dagger}$ & $369.02-1422.90$ & \\
\hline & Female & 906 & 910 & 254.62 & 22.16 & 863- 950 & $397-1415^{\dagger}$ & $413.34-1641.76$ & $<0.001$ \\
\hline \multirow[t]{2}{*}{ CD8\% } & Male & 29.65 & 29.30 & 5.59 & 0.51 & $28.65-30.65$ & $18.47-40.83^{\dagger}$ & $17.2-45.2$ & \\
\hline & Female & 28.51 & 27.95 & 7.38 & 0.64 & $27.25-29.76$ & $13.74-43.27^{\dagger}$ & $11.6-50.6$ & 0.073 \\
\hline \multirow[t]{2}{*}{ CD8 - SPT } & Male & 586 & 552 & 196.98 & 17.91 & $551-621$ & $296-1077^{\star}$ & $179-1261$ & \\
\hline & Female & 587 & 562 & 218.22 & 18.99 & $550-624$ & $204-1013^{\star}$ & $172-1476$ & 0.456 \\
\hline \multirow[t]{2}{*}{ CD8 - DPT } & Male & 645 & 585 & 221.67 & 20.15 & $606-685$ & $355-1171^{*}$ & $311.17-1350.44$ & \\
\hline & Female & 626 & 584 & 220.13 & 19.16 & $589-664$ & $252-1139^{*}$ & $207.67-1458$ & 0.337 \\
\hline \multirow[t]{2}{*}{ Ratio } & Male & 1.30 & 1.22 & 0.37 & 0.03 & $1.24-1.37$ & $0.72-2.10^{\star}$ & $0.61-2.55$ & \\
\hline & Female & 1.58 & 1.49 & 0.61 & 0.05 & $1.48-1.68$ & $0.65-2.96^{\star}$ & $0.54-3.89$ & $<0.001$ \\
\hline
\end{tabular}

a $95 \%$ confidence interval, ${ }^{\star} 2.5^{\text {th }}$ and $97.5^{\text {th }}$ percentile values of the sample, ${ }^{\dagger}$ Mean $\pm 2 S D$, ${ }^{c}$ Minimum and Maximum of sample values 
Table 3: Comparison of values from the present study with published reference values

\begin{tabular}{|c|c|c|c|c|c|c|c|c|}
\hline & Present study & & India & & Asian & Chinese & Botswana & UK \\
\hline & & $\begin{array}{l}\text { Singh } \\
\text { et } a l^{\star}[9]\end{array}$ & $\begin{array}{c}\text { Uppal } \\
\text { et } a l^{*}[10]\end{array}$ & $\begin{array}{l}\text { Saxena } \\
\text { et a/t [11] }\end{array}$ & $\begin{array}{c}\text { Wee } \\
\text { et } a^{\prime t ~[14] ~}\end{array}$ & $\begin{array}{c}\text { Jiang } \\
\text { et } a l^{*}[16]\end{array}$ & $\begin{array}{c}\text { Bussmann } \\
\text { et alt [15] }\end{array}$ & $\begin{array}{c}\text { Bofill } \\
\text { et } a^{*}[17]\end{array}$ \\
\hline ALC cells $/ \mathrm{mm}^{3}$ & 2198 & NM & 2114 & NM & 2375 & NM & NM & 1900 \\
\hline CD4 cells $/ \mathrm{mm}^{3}$ & 771 & 848 & 865 & NM & 838 & 727 & 726 & 830 \\
\hline \%CD4 & 38.8 & 36 & 40.2 & 37 & 35.6 & NM & NM & 43.6 \\
\hline CD8 cells $/ \mathrm{mm}^{3}$ & 555 & 427 & 552 & NM & 642 & 539 & 488 & 560 \\
\hline$\% C D 8$ & 28.6 & 21 & 31.3 & 34 & 27 & NM & NM & 29.5 \\
\hline CD4:CD8 & 1.34 & 1.99 & 1.7 & 1.16 & 1.43 & 1.49 & 1.57 & 1.51 \\
\hline
\end{tabular}

ALC, absolute lymphocyte count; $\mathrm{Cl}$, confidence interval; NM, not mentioned, ${ }^{\mathrm{D}} \mathrm{DPT},{ }^{\dagger} \mathrm{SPT}$

a difference of greater than 50 cells $/ \mathrm{mm}^{3}$. Regression analysis was done to compare the correlation between the two techniques. The correlation coefficient $\mathrm{R}$ for $\mathrm{CD} 3$ counts was 0.76 , for CD4 counts 0.84 and for CD8 counts 0.88 . When the values obtained by the two techniques were again analyzed for statistical significance by the Students $t$ test using paired sample criteria statistically significant difference $P<0.001$ was seen for CD3, CD4 as well as CD8 counts [Figure 3].

Values obtained by the SPT have been used to establish the reference range.

\section{DISCUSSION}

The value of lymphocyte subsets obtained in our population is different from those of the other populations [Table 3]. Our study is at variance with values obtained in the Indian cohort as well as the Chinese and Malaysian populations of a multi-racial study. ${ }^{[14]}$ Interestingly the study employed SPT but a different protocol (Trucount tubes). Our results are however similar to that of the population from Botswana ${ }^{[15]}$ and China. ${ }^{[16]}$ In the Indian scenario, the study from Western India ${ }^{[10]}$ has enumerated higher counts and reported that these are similar to adult Caucasians. ${ }^{[17]}$ The multi centric study from India ${ }^{[11]}$ has given the national means of percentages of lymphocytes as CD3 $68.65 \%$, CD4 $34.04 \%$ and CD8 14.67\%. The values of the lymphocyte subsets in our study, are higher, which could be ethnicity related (lower values of lymphocyte population have been reported for South Indian population, ${ }^{[18]}$ which also forms a part of this multi centric study) or method related (gating strategy was based on forward-side scatter plot).

Gender specific variation in absolute CD4 and CD8 counts has been seen in our study [Table 2]. These results are akin to many other studies, which have reported that males have higher CD8 percentages and females have higher CD4 percentages. ${ }^{[5,19,20]}$ Differences in immune cell numbers between genders may be secondary to the differential influences of sex hormones shown in murine studies. ${ }^{[21]}$

The impact of age on lymphocyte subsets is not well established. Some studies have shown that the number of $\mathrm{CD}^{+}$cells increased while the number of $\mathrm{CD}^{+}$decreased with age, ${ }^{[22,23]}$ while others state that the numbers of both $\mathrm{CD}^{+}$ and $\mathrm{CD}^{+}$increase with age. ${ }^{[24]}$ Our results do not show any significant differences in the percentages of CD4 and CD8 as well as the CD4:CD8 ratio with respect to age [Figure 2]. 


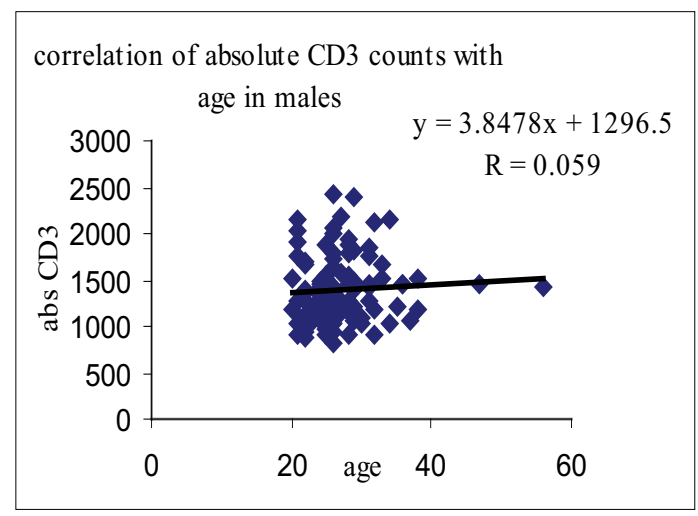

correlation of absolute CD4 counts with

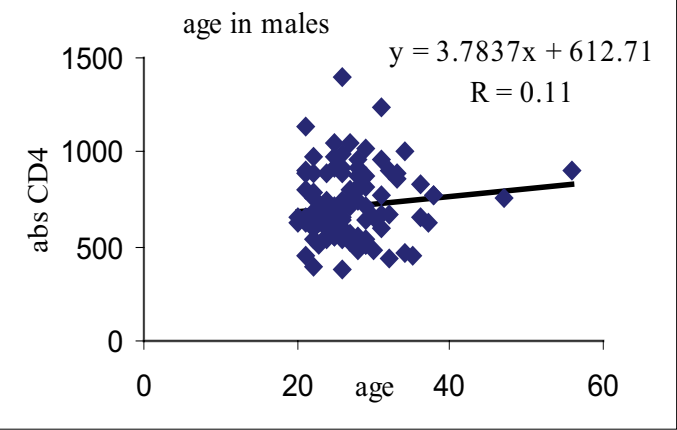

correlation of absolute CD8 counts with

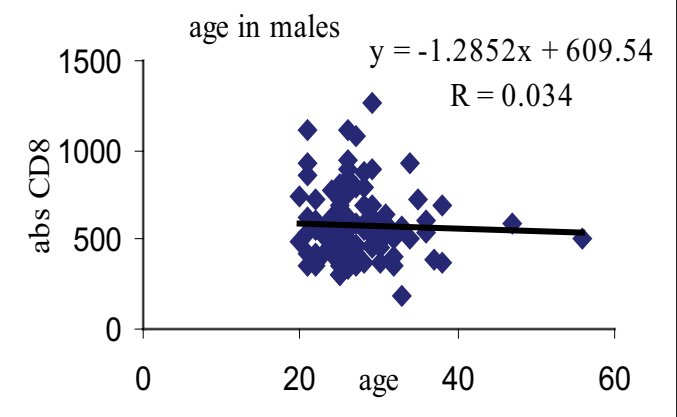

Figure 2(A): Correlation of absolute lymphocyte subsets counts with age, Regression Analysis: lymphocyte subsets with age in males, 1) correlation between age and absolute CD3 counts, 2) correlation between age and absolute CD4 counts, 3) correlation between age and absolute CD8 counts. correlation of absolute CD3 counts

with age in females
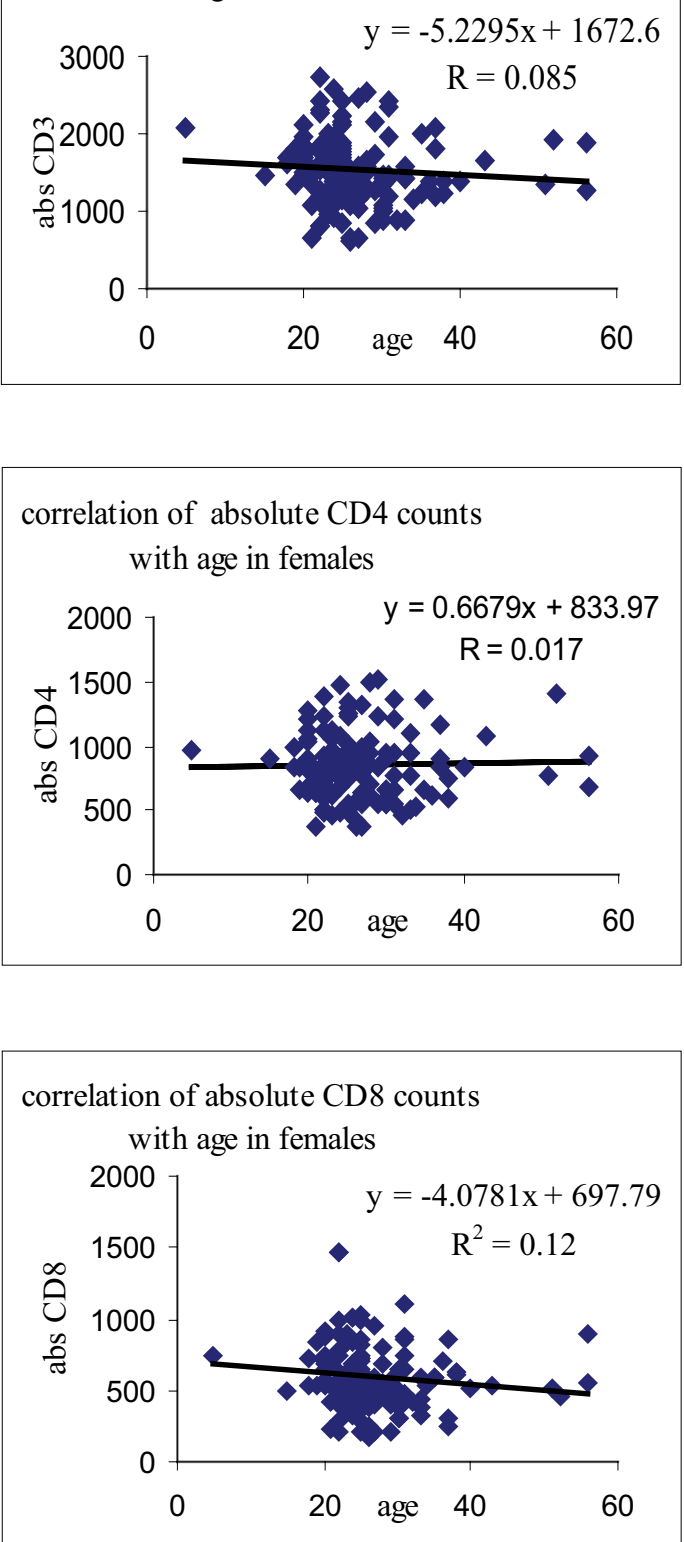

Figure 2(B): Correlation of absolute lymphocyte subsets counts with age, Regression Analysis: lymphocyte subsets with age in females, 1) correlation between age and absolute CD3 counts, 2) correlation between age and absolute CD4 counts, 3) correlation between age and absolute CD8 counts. 
A multi centric study ${ }^{[25]}$ had highlighted three major reasons for interlaboratory variability: variations in sample processing, suboptimal lymphocyte gating that uses light scattering and variations in white cell count measurement. Other studies have also shown that the major source of interlaboratory variation in lymphocyte subset enumeration is the automated blood analyzer when DPT is used. ${ }^{[26,27]}$ This source of variation can be eliminated by the SPT that is adopted in this study.

\section{CONCLUSION}

We have established reference ranges for the lymphocyte subsets for healthy Western Indians using the tetraONE System (which has automated CD45 lymphocyte gating and analysis and fluorosphere-derived absolute counting) and following the latest guidelines. Our study reveals that the lymphocyte subsets in our population are closer to those of the population from Botswana, and China than the Western population, and this needs to be taken into account while devising protocols for the treatment of individuals with HIV. Our study also confirms the gender difference in the lymphocyte subset counts, however the impact of age is less certain.

\section{REFERENCES}

1. Smith RD. The pathobiology of HIV infection. Arch Pathol Lab Med 1990;114:235-39.

2. Sankaran JR. Current situation of HIV/AIDS in India and our response. Indian Acad Clin Med 2006;7:13-5.

3. Mellors JW, Munoz A, Giorgi JV, Margolick JB, Tassoni CJ, Gupta P, et al. Plasma viral loads and CD41 lymphocytes as prognostic markers of HIV-1 infection. Ann Intern Med 1997;126:

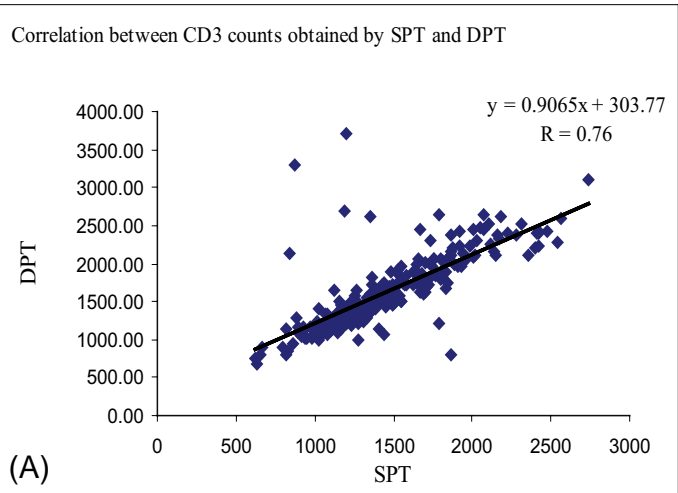

correlation between CD4 counts obtained by SPT and DPT

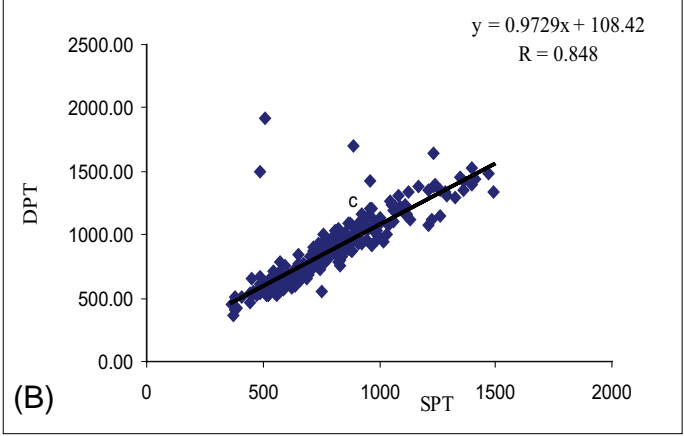

correlation between CD8 counts obtaibed by SPT and DPT

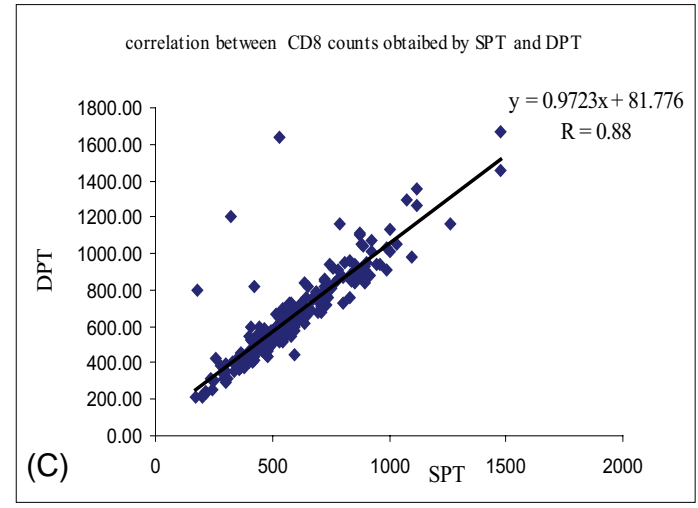

Figure 3:Linear regression analysis of absolute lymphocyte subsets counts with the method of enumeration, (A) correlation of the absolute CD3 counts, (B) correlation of the absolute CD4 counts and (C) correlation of the absolute CD8 counts.

946-54.

4. Piketty C, Castiel P, Belec L, Batisse D, Mohamed AS, Gilquin J, et al. Discrepant responses to triple 
combination antiretroviral therapy in advanced HIV disease. AIDS 1998;12:745-50.

5. Maini MK, Gilson RJ, Chavda N, Gill S, Fakoya A, Ross EJ, et al. Reference ranges and sources of variability of CD4 counts in HIV-seronegative women and men. Genitourin Med 1996;72: 27-31.

6. Brando B, Barnett D, Janossy G, Mandy F, Autran $B$, Rothe $G$, et al. Cytofluorometric methods for assessing absolute numbers of cell subsets in blood. Cytometry 2000;42:327-46.

7. Reimann KA, O'Gorman MR, Spritzler J, Wilkening CL, Sabath DE, Helm K, et al. Multisite comparison of CD4 and CD8 T-lymphocyte counting by single- versus multiple-platform methodologies: Evaluation of Beckman Coulter flow-count fluorospheres and the tetraONE System. Clin Diagn Lab Immunol 2000;7: 344-51.

8. Higgins J, Hill V, Lau K, Simpson V, Roayaei J, Klabansky R, et al. Evaluation of a single platform technology for lymphocyte immunophenotyping. Clin Vaccine Immunol 2007;14:1342-8.

9. Singh YG, Dar L, Singh NG. Levels of CD4 and CD8 among the inhabitants of Manipur. Indian J Commun Dis 2000;32:201-6.

10. Uppal SS, Verma S, Dhot PS. Normal values of CD4 and CD8 lymphocyte subsets in healthy Indian adults and the effects of sex, age, ethnicity, and smoking. Cytometry Part B (Clinical Cytometry) 2003;52:32-6.

11. Saxena RK, Choudhry V, Nath I, Das SN, Paranjape S, Babu G, et al. Normal ranges of some select lymphocyte sub-populations in peripheral blood of normal healthy Indians. Curr Sci 2004;86:969-75.

12. Calvelli T, Denny TN, Paxton H, Gelman R, Kagan J. Guideline for flowcytometric immunophenotyping: A report from the National Institute of Allergy and Infectious Disease, Division of AIDS. Cytometry 1993;14:702-15.

13. Centers for Disease Control and Prevention. 1997 revised guidelines for performing CD4+ T-cell determinations in persons infected with human immunodeficiency virus (HIV). MMWR Morbid Mortal Weekly Rep 1997;46:1-29.

14. Chng WC, Tan GB, Kuperan P. Establishment of adult peripheral blood lymphocyte subset reference range for an Asian population by single platform flow cytometry: Influence of age, sex and race and comparison with other published studies. Clin Diagn Lab Immunol 2004;11:168-73.

15. Bussmann H, Wester WC, Masupu KV, Peter $\mathrm{T}$, Gaolekwe, Kim Soyeon K, et al. Low CD4+ T-lymphocyte values in human immunodeficiency virus-negative adults in Botswana. Clin Diagn Lab Immunol 2004;11:930-5.

16. Jiang $W$, Kang $L$, Lu HZ, Xiaozhang LQ, Lin $Q$, Pan $Q$, et al. Normal Values for CD4 and CD8 lymphocytes in healthy Chinese adults from Shanghai. Clin Diagn Lab Immunol 2004;11:811-3.

17. Bofill M, Janossy G, Lee CA, MacDonaldBurns D, Phillips AN, Sabin C, et al. Laboratory control values for CD4 and CD8 T lymphocytes: Implications for HIV-1 diagnosis. Clin Exp Immunol 1992;88:243-52.

18. Ramalingam S, Kannangai $R$, Zachariah A, Mathai D, Abraham C. CD4 counts of normal and HIV-infected South Indian adults: Do we need a new staging system? Natl Med J India 2001;14:335-9.

19. Lee BW, Yap HK, Chew FT, Quah TC, Prabhakaran $\mathrm{K}$, Chan GS, et al. Age and sex related changes in lymphocyte subpopulations of healthy Asian subjects: From birth to adulthood. Cytometry 1996;26:8-15.

20. Choong ML, Yon SH, Cheong SK. Influence of race, age and sex on the lymphocyte subsets in peripheral blood of healthy Malaysian adults. Ann Clin Biochem 1995;32:532-9.

21. McMurray RW, Hoffman RW, Nelson W, Walker SE. Cytokine mRNA expression in the B/W mouse model of systemic lupus erythematosis-analysis of strain, gender and age effects. Clin Immunol Pathol 1997;84:260-8. 
22. Denny T, Yogev R, Gelman R, Skuza C, Oleske $\mathrm{J}$, Chadwick E, et al. Lymphocyte subsets in healthy children during the first 5 years of life. JAMA1992;267:1481-8.

23. Tollerud DJ, Ildstad ST, Brown LM, Clark JW, Blattner WA, Mann DL, et al. T-cell subsets in healthy teenagers: Transition to the adult phenotype. Clin Immunol Immunopathol 1990;56:88-96.

24. Wiener D, Shah S, Malone J, Lowell N, Lowell S, Rowlands DT Jr. Multiparametric analysis of peripheral blood in normal paediatric population by Flow Cytometry. J Clin Lab Anal 1990;4:175-9.

25. Gratama JW, Kraan J, Van den Beemd R, Hooibrink B, Van Bockstaele DR, Hooijkaas $\mathrm{H}$. Analysis of variation in results of flowcytometric lymphocyte immunophenotyping in a multicenter study. Cytometry 1997;30:166-77.
26. Lau L, Tan GB, Kuperan P. CD4 lymphocyte enumeration in patients with human immunodeficiency virus infection using threecolour and four-colour dual-platform flow Cytometry: An interlaboratory comparative evaluation. Ann Acad Med Sing 2002;31: 765-71.

27. O'Gorman MR, Gelman R; Site Investigators and the NIAID New CD4 Technologies Focus Group. Inter-and intrainstitutional evaluation of automated volumetric capillary Cytometry for the quantification of CD4- and CD8-positive T lymphocytes in the peripheral blood of persons infected with immunodeficiency virus. Clin Diagn Lab Immunol 1997;4:173-9.

Source of Support: Nil, Conflict of Interest: None declared. 